\title{
EVALUASI KEBIJAKAN PEMBERDAYAAN EKONOMI PEREMPUAN MELALUI PROGRAM DESA PEREMPUAN INDONESIA MAJU MANDIRI (PRIMA) DI KELURAHAN LOK BAHU KECAMATAN SUNGAI KUNJANG KOTA SAMARINDA
}

\section{POLICY EVALUATION OF WOMEN'S ECONOMIC EMPOWERMENT THROUGH PRIMA VILLAGE PROGRAM IN SAMARINDA (STUDY IN LOK BAHU VILLAGE, SUNGAI KUNJANG SUB-DISTRICT SAMARINDA CITY)}

\author{
Ratih Fenty A. Bintoro*, Abdullah Karim**, Enos Paselle** \\ *Balitbangda Prov. Kaltim \\ Jl. MT. Haryono 126 Samarinda 75124 \\ Email: fentybintoro@gmail.com \\ **Universitas Mulawarman \\ Jl. Kuaro, Samarinda 75119
}

Diterima: 30 Oktober 2020; Direvisi: 14 Desember 2020; Disetujui: 22 Desember 2020

\begin{abstract}
ABSTRAK
Hasil Susenas Tahun 2010 menunjukkan bahwa jumlah penduduk laki laki sebesar 50,17 persen, sedangkan perempuan sebesar 49,83 persen. Walaupun jumlahnya hampir seimbang, namun fakta empiris menunjukkan bahwa kualitas hidup perempuan masih lebih rendah daripada kaum laki-laki. Perempuan mengalami ketertinggalan dalam banyak hal, salah satunya ketertinggalan dalam aspek ekonomi. Berbagai upaya dalam menyelesaikan ketertinggalan tersebut telah dilakukan oleh berbagai pihak contohnya Kementerian Pemberdayaan Perempuan melalui program Desa Perempuan Indonesia Maju Mandiri (PRIMA). Penelitian ini bertujuan untuk mengevaluasi pelaksanaan kebijakan pemberdayaan ekonomi perempuan melalui program Desa Perempuan Indonesia Maju Mandiri (PRIMA) di Kelurahan Lok Bahu Kecamatan Sungai Kunjang Kota Samarinda dengan fokus penelitian pada aspek relevansi, efektivitas serta keberlanjutan program. Penelitian ini menggunakan metode penelitian kombinasi (mixed methods) untuk mendapatkan deskripsi yang mendalam tentang pelaksanaan program Desa PRIMA di Kelurahan Lok Bahu Kecamatan Sungai Kunjang Kota Samarinda serta faktor pendukung dan penghambat pelaksanaan progam tersebut. Data didapatkan melalui penyebaran kuesioner, wawancara, observasi dan dokumentasi. Hasil penelitian menunjukkan bahwa program Desa PRIMA memenuhi kriteria relevansi (relevan dengan kebutuhan perempuan), efektivitas (ketepatan sasaran program dan pencapaian tujuan program khususnya untuk peningkatan keterampilan manajemen usaha serta peningkatan pendapatan) dan keberlanjutan (layak untuk dilanjutkan). Namun program ini tidak memenuhi kriteria efektivitas peningkatan kesejahteraan keluarga. Faktor yang mendukung pelaksanaan Desa PRIMA adalah dukungan kondisi lingkungan, hubungan antar organisasi serta sumber daya manusia. Sedangkan yang menghambat adalah sumber daya finansial (anggaran). Rekomendasi yang dapat diberikan adalah perlunya pemetaan kebutuhan materi pelatihan, perlunya peningkatan motivasi kewirausahaan dan pembangunan jejaring antar pelaku usaha serta komitmen anggaran untuk keberlanjutan program.
\end{abstract}

Kata kunci: Pemberdayaan Perempuan, Desa PRIMA, Samarinda. 
Evaluasi Kebijakan Pemberdayaan Ekonomi Perempuan Melalui Program Desa Perempuan Indonesia Maju Mandiri (Prima) di Kelurahan Lok Bahu Kecamatan Sungai Kunjang Kota Samarinda

Ratih Fenty A. Bintoro, Abdullah Karim, Enos Paselle

ABSTRACT

The results of SUSENAS 2010 show that the total male population is 50,17\%, while the female population is 49,83\%. Although the numbers are almost equal, empirical facts show that the quality of life for women is still lower than men. Women are left behind in many ways, for example in economic aspect. Various parties have made various efforts to resolve this gap, for example the Ministry of Women's Empowerment through PRIMA Village program. This study aims to evaluate the implementation of women's economic empowerment policies through PRIMA Village program in Lok Bahu Village, Sungai Kunjang Subdistrict, Samarinda City, with a research focus on aspects of relevance, effectiveness and sustainability of the program. This study uses mixed methods in order to get description about the implementation of the PRIMA Village program and also the supporting and inhibiting factors for the implementation of the program. Data obtained through questionnaires, interviews, observation and documentation. The results show that the PRIMA Village program meets the criteria of relevance (relevant to the needs of women), effectiveness (accuracy of program goals and achievement of program objectives specifically for improving business management skills and increasing income) and sustainability (worth continuing). However, this program does not meet the effectiveness criteria for improving family welfare. The supporting factors of the implementation of PRIMA Village are the support of environmental conditions, relations between organizations and human resources. Whereas the obstacle is financial resources (budget). Recommendations that can be given are the need to map training material needs, the need to increase entrepreneurial motivation and build networks among business actors as well as a budget commitment for program sustainability.

Keywords : Women's Empowerment, PRIMA Village, Samarinda.

\section{PENDAHULUAN}

Hasil Susenas Tahun 2010 menunjukkan bahwa secara nasional jumlah penduduk Indonesia sebesar 237,5 juta jiwa dimana jumlah penduduk laki-laki lebih banyak dibandingkan perempuan. Persentase penduduk laki-laki sebesar 50,17 persen, sedangkan perempuan sebesar 49,83 persen. Walaupun jumlahnya hampir seimbang, namun fakta empiris menunjukkan bahwa kualitas hidup perempuan masih lebih rendah daripada kaum laki-laki. Dengan kata lain, walaupun saat ini cukup banyak perempuan Indonesia yang menunjukkan bahwa dirinya mampu bersaing sekaligus memberikan kontribusi yang tidak kalah besarnya dalam berbagai bidang pembangunan, mulai dari ilmu pengetahuan, teknologi, politik, ekonomi, sosial, dan bahkan pertahanan dan keamanan, namun masih lebih banyak lagi perempuan Indonesia yang belum mampu menunjukkan potensi dan jati dirinya secara optimal karena masih terkungkung oleh keterbatasan/kemiskinan secara struktural, kultural, dan alamiah (KPPA, 2012:1).

Ketertinggalan perempuan dalam berbagai aspek pembangunan sangatlah jelas akan membawa dampak yang tidak menguntungkan bagi keseluruhan pembangunan jika tidak diperbaiki. Salah satunya adalah ketertinggalan dalam aspek ekonomi. Banyak faktor yang mempengaruhi ketertinggalan perempuan secara ekonomi diantaranya yaitu faktor kemiskinan, faktor motivasi dan faktor keterampilan. Perempuan tidak mampu berusaha karena beban kemiskinan, khususnya dalam pemenuhan pendidikan dan kesehatan, harus berusaha dengan segala cara dan berorientasi pada kebutuhan saat ini. Perempuan dalam keluarga miskin ini sulit untuk berpikir jernih dan terbuka dalam menata kehidupan masa depan. Sementara itu terdapat perempuan yang belum/tidak berusaha karena dihadapkan kepada permasalahan sikap, budaya, pengetahuan dan penerapan. Perempuan tidak berusaha karena kurangnya motivasi walaupun sumberdaya yang dimilikinya sebenarnya cukup atau mampu. Di lain pihak, ada perempuan ingin maju tetapi tidak memiliki pengetahuan atau keterampilan untuk usaha (KPPA, 2012:56).

Dalam upaya menyelesaikan permasalahan ekonomi perempuan yang kompleks ini, Kementerian Pemberdayaan Perempuan menetapkan Kebijakan Peningkatan Produktivitas 
Ekonomi Perempuan (PPEP) sebagai prioritas untuk meningkatkan kualitas hidup perempuan, disamping kebijakan untuk meningkatkan kualitas kesehatan, pendidikan serta perlindungan perempuan dan anak. Salah satu program Kebijakan Peningkatan Produktivitas Ekonomi Perempuan (PPEP) adalah model Desa Perempuan Indonesia Maju Mandiri (PRIMA) yang merupakan salah satu model peningkatan produktivitas ekonomi perempuan yang ditetapkan oleh Pemerintah Pusat dalam hal ini Kementerian Pemberdayaan Perempuan untuk diterapkan di daerah sejak tahun 2002. Model Desa Perempuan Indonesia Maju Mandiri (PRIMA) adalah sebuah desa percontohan yang bertujuan untuk menanggulangi kemiskinan sekaligus meningkatkan ekonomi perempuan dengan memanfaatkan semua potensi yang ada dan melibatkan segenap peran lintas sektoral terkait.

Model Desa Perempuan Indonesia Maju Mandiri (PRIMA) Kota Samarinda pertama kali ditetapkan di 2 (dua) kelurahan pada Tahun 2012 yaitu Kelurahan Bantuas dan Kelurahan Lok Bahu. Kemudian menyusul pada Tahun 2015, Kelurahan Lok Bahu dan Kelurahan Bandara turut ditetapkan menjadi model Desa Perempuan Indonesia Maju Mandiri (PRIMA). Desa Perempuan Indonesia Maju Mandiri (PRIMA) ditujukan bagi para wanita yang sudah mempunyai rintisan usaha rumahan agar lebih termotivasi untuk maju dengan jalan memberikan bimbingan manajemen usaha meliputi proses P-IRT, proses pengolahan pangan, pembukuan dan pembuatan proposal pengajuan bantuan usaha.

Namun sejak dibentuk, terdapat berbagai kendala yang dihadapi dalam rangka pembinaan Desa Perempuan Indonesia Maju Mandiri (PRIMA) seperti kurangnya komitmen pejabat terkait untuk terus memberdayakan perempuan melalui program Desa Perempuan Indonesia Maju Mandiri (PRIMA), penurunan anggaran yang berakibat pada kurangnya frekuensi untuk memberikan pelatihan dan juga motivasi perempuan untuk maju. Selain itu terdapat keluhan yang berasal dari kelompok sasaran yaitu kurang sesuainya materi pelatihan dibandingkan dengan kebutuhan terutama untuk usaha kecil yang mempunyai modal dan omset yang tidak terlalu besar. Melihat beberapa temuan awal terkait pelaksanaan program Desa Prima, maka penulis tertarik untuk melihat sejauh mana pelaksanaan kebijakan Desa Perempuan Indonesia Maju Mandiri (PRIMA) dalam upaya pemberdayaan ekonomi perempuan khususnya di Kelurahan Lok Bahu Kecamatan Sungai Kunjang Kota Samarinda.

\section{METODE}

Metode penelitian yang digunakan adalah metode penelitian kombinasi (mixed method). Data kuantitatif berupa hasil kuesioner kepada 29 anggota Desa PRIMA terkait indikator evaluasi program pelaksanaan Desa PRIMA Kelurahan Lok Bahu Kecamatan Sungai Kunjang Kota Samarinda. Sedangkan data kualitatif didapat dari wawancara mendalam kepada stakeholder terkait serta dokumen dokumen terkait pelaksanaan program Desa PRIMA. Fokus penelitian yaitu mengevaluasi program Desa Perempuan Indonesia Maju Mandiri (PRIMA) di Kelurahan Lok Bahu Kecamatan Sungai Kunjang dengan menggunakan indikator-indikator evaluasi program yang ditawarkan oleh Dale dalam Sardjo, Darmajanti dan Boediono (2016:23-30) yaitu Relevansi, Efektivitas dan Keberlanjutan. Selain itu juga mengidentifikasi faktor pendukung dan penghambat pelaksanaan kebijakan pemberdayaan ekonomi perempuan melalui program Desa Perempuan Indonesia Maju Mandiri (PRIMA) di Kota Samarinda.

\section{HASIL DAN PEMBAHASAN}

Sejalan dengan prioritas pembangunan Kota Samarinda khususnya terkait pemberdayaan masyarakat dan perempuan, dirumuskan berbagai program pemberdayaan salah satunya adalah Program Desa Perempuan Indonesia Maju Mandiri (PRIMA) yang merupakan salah satu upaya pengentasan kemiskinan yang melibatkan seluruh masyarakat untuk ikut membangun desa, sebagai upaya untuk meningkatkan kualitas hidup perempuan sekaligus mengentaskan 
kemiskinan desa melalui subsidi silang antar kelompok masyarakat yang berekonomi baik kepada masyarakat yang kurang beruntung.

Pemerintah Kota Samarinda telah menetapkan 4 (empat) kelurahan di Kota Samarinda sebagai model Desa PRIMA salah satunya adalah Desa Perempuan Indonesia Maju Mandiri (PRIMA) di Kelurahan Lok Bahu yang terbentuk pada tahun 2015 melalui SK Kepala Badan Pemberdayaan Masyarakat dan Perempuan No. 400/641/SK-PP.3.1/VIII/2015 tanggal 13 Agustus 2015 tentang Penunjukan Desa Perempuan Indonesia Maju Mandiri (PRIMA) Tingkat Kota Samarinda Kelurahan Lok Bahu Kecamatan Sungai Kunjang. Walaupun telah berjalan selama 4 (empat) tahun namun hingga saat ini belum ada evaluasi terkait program Desa Perempuan Indonesia Maju Mandiri (PRIMA) padahal evaluasi program sangat penting untuk dilakukan untuk mengetahui seberapa jauh dan bagian mana dari tujuan yang sudah tercapai dan bagian mana yang belum tercapai serta apa penyebabnya. Evaluasi program Desa PRIMA dalam penelitian ini diukur dari beberapa indikator sebagai berikut :

\section{Relevansi}

Relevansi menekankan pada apakah program kebijakan yang diimplementasikan tertuju/sesuai dengan masalah yang menjadi prioritas dari target program tersebut. Maka dari itu idealnya seluruh perencanaan program pembangunan harus disesuaikan dengan kebutuhan masyarakat sehingga dapat berjalan dengan efektif, efisien dan dapat menyelesaikan masalah yang ada, begitupun dengan program Desa PRIMA yang dibentuk dengan tujuan untuk menyelesaikan berbagai permasalahan perempuan di skala yang terkecil dengan melibatkan komunitas di sekitarnya. Program Desa PRIMA berupaya untuk menyelesaikan masalah masalah yang dihadapi oleh warga perempuan. Melalui kegiatan Bimbingan Manajemen Usaha, program ini berupaya untuk memberikan berbagai pengetahuan kepada warga perempuan untuk dapat memulai maupun mengembangkan usaha mereka.

Dilihat dari cakupan implementasi program terhadap permasalahan yang dihadapi warga perempuan dalam meningkatkan produktivitas ekonominya, program ini dinilai sudah dapat menyentuh berbagai permasalahan tersebut. Hal ini sesuai dengan jawaban 29 (dua puluh sembilan) warga perempuan yang menjadi anggota Desa Perempuan Indonesia Maju Mandiri (PRIMA) di Kelurahan Lok Bahu Kecamatan Sungai Kunjang dimana sebagian besar (79,31 $\%$ ) menyatakan bahwa program Desa Perempuan Indonesia Maju Mandiri (PRIMA) sesuai dengan kebutuhan warga perempuan di Kelurahan Lok Bahu Kecamatan Sungai Kunjang sedangkan sisanya sebanyak 20,69\% memilih untuk tidak menjawab/tidak tahu.

Jika dikaitkan dengan pendapat Hadi (2009:13), relevansi program dengan kebutuhan menjadi penting mengingat dari pengalaman bahwa berbagai program pemberdayaan masyarakat banyak mengalami kegagalan karena pendekatan "target" dan "top-down" program seringkali menetapkan tujuan tanpa melibatkan kelompok sasaran program itu sendiri.

\section{Efektivitas}

Efektivitas menunjukan pada apakah output yang direncanakan, perubahan yang diharapkan serta efek dan dampak yang ingin dicapai telah terhasilkan atau tercapai. Budiani (2007:52) menyatakan bahwa untuk mengukur faktor faktor yang dapat mempengaruhi berjalan atau tidaknya suatu program dapat dilakukan dengan menggunakan variabel-variabel seperti ketepatan sasaran program dan pencapaian tujuan program. Dalam penelitian ini ketepatan sasaran program dilihat dari latar belakang peserta dan jumlah peserta bimbingan manajemen usaha yang merupakan program Desa PRIMA. Program Desa Perempuan Indonesia Maju Mandiri (PRIMA) ditujukan bagi para wanita yang sudah mempunyai rintisan usaha rumahan agar lebih termotivasi untuk maju dengan jalan memberikan bimbingan manajemen usaha. Partisipasi warga perempuan untuk mengikuti pelatihan bimbingan manajemen usaha yang 
merupakan program dari Desa PRIMA terbilang cukup tinggi. Kegiatan bimbingan manajemen usaha dikuti oleh 40 (empat puluh) peserta dengan berbagai latar belakang usaha dari total 65 Usaha Kecil Menengah yang terdaftar di Kelurahan Lok Bahu. Sedangkan dari indikator pencapaian tujuan program dilihat dari aspek peningkatan pendapatan, peningkatan kesejahteraan keluarga dan peningkatan keterampilan manajemen usaha. Untuk aspek peningkatan pendapatan, program Desa PRIMA dirasakan signifikan berpengaruh terhadap peningkatan pendapatan perempuan di Kelurahan Lok Bahu Kecamatan Sungai Kunjang (79,31 $\%)$. Sementara itu untuk aspek peningkatan kesejahteraan keluarga, sebagian besar responden $(89,66 \%)$ menyatakan bahwa program Desa PRIMA dinilai tidak terlalu dapat meningkatkan kesejahteraan keluarga. Kesulitan pencapaian tujuan peningkatan kesejahteraan keluarga ini dikarenakan kebanyakan para perempuan pengusaha masih merasa bahwa tugas mencari nafkah ada di tangan laki laki dalam hal ini suami mereka. Selain alasan di atas, skala usaha yang kecil dimana usaha yang dilakukan hanya sambilan untuk menunjang kebutuhan rumah tangga dianggap tidak berpengaruh besar pada peningkatan kesejahteraan.

Terakhir, untuk aspek peningkatan keterampilan manajemen usaha, dari jawaban 29 (dua puluh Sembilan) responden warga perempuan yang menjadi anggota Desa Perempuan Indonesia Maju Mandiri (PRIMA) di Kelurahan Lok Bahu Kecamatan Sungai Kunjang didapatkan hasil bahwa sebagian besar responden $(58,62 \%)$ merasakan adanya peningkatan keterampilan untuk pengembangan usaha mereka pasca mengikuti kegiatan bimbingan manajemen usaha maupun pelatihan menjahit, sedangkan sebanyak 41,38 \% menyatakan tidak ada perubahan pasca mengikuti kegiatan dimaksud.

Namun selain manfaat yang dirasakan, terdapat informan yang mengeluhkan mengenai materi pelatihan yang dirasa rumit untuk diaplikasikan mengingat skala usahanya yang masih kecil dan belum membutuhkannya sehingga tidak terlalu berdampak untuk pengembangan usaha.

"Ada pelatihan, tentang manajemen sedangkan usaha kita usaha kecil, kalau kita belanja belanja suruh masukan, bikin pembukuan, kalau kita ibu ibu ini agak ribet kalau begitu soalnya kita ini kan ekonomi kecil. Modalnya di bawah 5 juta, dapat untung kita belanjakan lagi, diputar buat jualan lagi" (Wawancara dengan Ibu Tanti, Usaha Pentol Goreng).

\section{Keberlanjutan}

Keberlanjutan merujuk pada kemampuan program untuk dapat terus berjalan bahkan ketika sumber daya yang diinvestasikan oleh penyelenggara program sudah dihapuskan. Berbicara mengenai investasi sumber daya, program Desa Perempuan Indonesia Maju Mandiri (PRIMA) termasuk dalam Rencana Strategis Dinas Pemberdayaan Perempuan dan Perlindungan Anak Kota Samarinda Tahun 2016-2021 sebagai indikator kinerja pelayanan Dinas Pemberdayaan Perempuan dan Perlindungan Anak Kota Samarinda khususnya untuk program peningkatan peran serta dan kesetaraan gender dalam pembangunan. Walaupun merupakan salah satu indikator kinerja pelayanan Dinas Pemberdayaan Perempuan dan Perlindungan Anak Kota Samarinda, namun dalam pelaksanaanya program ini tidak termasuk dalam program kegiatan prioritas yang mendapatkan anggaran. Kondisi keuangan Pemerintah Kota Samarinda yang defisit membuat setiap instansi termasuk Dinas Pemberdayaan Perempuan dan Perlindungan Anak Kota Samarinda harus mengambil langkah bijak untuk memilah milah program kegiatan yang dapat dilaksanakan setiap tahunnya. Maka dari itu semenjak dibentuk, kegiatan pembinaan yang dilakukan masih terbatas frekuensinya, bahkan selama 2 (dua) tahun yaitu tahun 2016-2017 vakum dilakukan pembinaan. Namun walapun tidak mendapatkan anggaran, Dinas Pemberdayaan Perempuan dan Perlindungan Anak Kota Samarinda tetap berupaya mensiasatinya dengan bekerjasama dengan Dinas Kependudukan Pemberdayaan Perempuan dan Perlindungan Anak Provinsi Kaltim untuk memberikan 
bimbingan dan pelatihan bagi warga perempuan khususnya yang berada di Desa PRIMA. Beberapa pelatihan yang dilakukan merupakan pelatihan dalam manajemen usaha baik berupa pelatihan keterampilan, produksi, pemasaran maupun manajemen pembukuan.

Dari hasil jawaban responden warga perempuan di Kelurahan Lok Bahu Kecamatan Sungai Kunjang yang dijabarkan sebelumnya, program Desa Perempuan Indonesia Maju Mandiri (PRIMA) dengan kegiatan yang dilakukannya dianggap sesuai dengan kebutuhan/permasalahan yang dihadapi dan juga dapat meningkatkan pendapatan usaha. Melihat ketepatan tujuan dan peningkatan hasil, keberlanjutan program ini dibutuhkan untuk dilakukan. Hasil kuesioner menunjukan sebanyak 89,66 \% responden menyatakan bahwa program Desa Perempuan Indonesia Maju Mandiri (PRIMA) layak dipertahankan/dilanjutkan, sedangkan sisanya sebanyak $10,34 \%$ memilih menjawab tidak tahu.

Kebutuhan akan program pemberdayaan yang fokusnya untuk peningkatan ekonomi menjadi titik penentu kebutuhan akan keberlanjutan program Desa Perempuan Indonesia Maju Mandiri (PRIMA) dengan berbagai kegiatannya. Dari hasil observasi peneliti, pada dasarnya program pemberdayaan ekonomi perempuan ada bermacam macam jenisnya dengan sasaran program yang sama dan cenderung tumpang tindih. Di Kelurahan Lok Bahu, terdapat beberapa program pemberdayaan ekonomi perempuan yang serupa dengan program Desa Perempuan Indonesia Maju Mandiri (PRIMA), salah satunya adalah program UPPKS (Usaha Peningkatan Pendapatan Keluarga Sejahtera) yang merupakan program BKKBN (Badan Koordinasi Keluarga Berencana Nasional). Untuk tingkat kota dikoordinir oleh Dinas Kependudukan, Pemberdayaan Perempuan dan Perlindungan Anak Kota Samarinda.

Serupa dengan progam Desa Perempuan Indonesia Maju Mandiri (PRIMA), Program UPPKS juga memberikan keterampilan kepada warga perempuan, bedanya adalah UPPKS juga memberikan pinjaman modal usaha dengan metode tanggung renteng sedangkan Program Desa Perempuan Indonesia Maju Mandiri (PRIMA) fokus memberikan bimbingan manajemen usaha, tentang bagaimana mengelola dan mengembangkan usaha yang telah dirintis agar dapat lebih berkembang lagi. Untuk itu bantuan pemerintah yang kontinu dalam hal bimbingan usaha sangat diperlukan sehingga tercipta kondisi perempuan yang mandiri dan dapat membantu menopang kesejahteraan keluarga yang muaranya pada kemandirian wilayah (desa/kelurahan).

Dalam pelaksanaannya, terdapat beberapa faktor pendukung maupun penghambat pelaksanaan program Desa PRIMA. Faktor pendukung pelaksanaan program adalah kondisi lingkungan, hubungan antar organisasi dan sumberdaya manusia. Kondisi lingkungan yang kondusif terkait partisipasi aktif warga perempuan untuk berpartisipasi dalam program, kerjasama yang baik antar lembaga terkait dalam memberikan materi pelatihan dan juga SDM yang kompeten dalam bidang pelatihan merupakan faktor yang mempengaruhi keberhasilan pelaksanaan program.

Namun terdapat faktor penghambat pelaksanaan program berupa keterbatasan anggaran. Walaupun dalam Renstra Dinas Pemberdayaan Perempuan dan Perlindungan Anak Kota Samarinda masuk sebagai indikator kinerja pelayanan DP3A Kota Samarinda Tahun 20162021, namun program Desa PRIMA tidak masuk dalam program kerja prioritas yang mendapatkan anggaran dikarenakan defisit keuangan Pemkot Samarinda.

\section{KESIMPULAN}

Desa PRIMA (Perempuan Indonesia Maju Mandiri) Kelurahan Lok Bahu Kecamatan Sungai Kunjang Kota Samarinda dibentuk pada Tahun 2015 dengan tujuan untuk meningkatkan ekonomi perempuan dengan memanfaatkan semua potensi yang ada dan melibatkan segenap peran lintas sektoral terkait. Berdasarkan hasil penelitian mengenai evaluasi program Desa PRIMA di Kelurahan Lok Bahu Kecamatan Sungai Kunjang Kota Samarinda dapat disimpulkan sebagai berikut : 
1. Evaluasi pelaksanaan program Desa PRIMA di Kelurahan Lok Bahu Kecamatan Sungai Kunjang Kota Samarinda, dilihat dari indikator evaluasi program yang ditawarkan oleh Dale dalam Sardjo, Darmajanti dan Boediono (2016:23-30) adalah sebagai berikut :

\section{a. Relevansi}

Sesuai dengan hasil kuesioner dan wawancara dengan anggota Desa PRIMA Kelurahan Lok Bahu Kecamatan Sungai Kunjang Kota Samarinda, Program Desa PRIMA dinilai relevan dengan kebutuhan warga perempuan di Kelurahan Lok Bahu Kecamatan Sungai Kunjang Kota Samarinda untuk meningkatkan pengetahuan dan keterampilan usaha.

\section{b. Efektivitas}

Hasil kuesioner dan wawancara menunjukan bahwa program Desa PRIMA dinilai efektif dari aspek ketepatan sasaran program dan pencapaian tujuan program khususnya untuk pencapaian tujuan peningkatan pendapatan perempuan dan peningkatan keterampilan manajemen usaha walaupun terdapat keluhan mengenai materi program yaitu perihal pembukuan usaha yang dianggap tidak sesuai dengan kebutuhan beberapa peserta karena dinilai terlalu rumit untuk skala usaha kecil. Namun di sisi lain untuk pencapaian tujuan peningkatan kesejahteraan keluarga dinilai belum efektif dikarenakan skala usaha yang kecil dan sebagian besar pengusaha perempuan masih menganggap usaha mereka adalah usaha sambilan bukan merupakan mata pencaharian utama (masih bergantung pada penghasilan suami).

\section{c. Keberlanjutan}

Program Desa PRIMA dinilai sesuai dengan kebutuhan/permasalahan warga perempuan di Kelurahan Lok Bahu Kecamatan Sungai Kunjang Kota Samarinda sehingga keberadaan program ini dinilai layak untuk dipertahankan/dilanjutkan dan diarahkan untuk bersinergi dengan program sejenis dari instansi lainnya seperti program Usaha Peningkatan Pendapatan Keluarga Sejahtera (UPPKS) dari Badan Kependudukan dan Keluarga Berencana Nasional (BKKBN), Usaha Peningkatan Pendapatan Keluarga (UP2K) dari Tim Penggerak Pemberdayaan Kesejahteraan Keluarga (PKK) dan lain lain. Hal ini sesuai hasil kuesioner dan wawancara dengan warga perempuan anggota Desa PRIMA di Kelurahan Lok Bahu Kecamatan Sungai Kunjang Kota Samarinda.

2. Faktor pendukung dan penghambat pelaksanaan program Desa PRIMA (Perempuan Indonesia Maju Mandiri) di Kelurahan Lok Bahu Kecamatan Sungai Kunjang Kota Samarinda yang teridentifikasi berdasarkan hasil wawancara adalah sebagai berikut :

a. Kondisi lingkungan. Kondisi lingkungan menjadi faktor pendukung pelaksanaan program Desa Prima di Kelurahan Lok Bahu Kecamatan Sungai Kunjang Kota Samarinda dilihat dari partisipasi warga perempuan yang tinggi untuk berperan aktif dalam kegiatan bimbingan manajemen usaha yang merupakan program kegiatan Desa PRIMA.

b. Hubungan antar organisasi. Hubungan antar organisasi menjadi faktor pendukung pelaksanaan program Desa PRIMA di Kelurahan Lok Bahu Kecamatan Sungai Kunjang Kota Samarinda karena adanya koordinasi yang baik antar instansi vertikal maupun horizontal untuk mendukung pelaksanaan program Desa PRIMA terutama dalam pemberian materi pelatihan bimbingan manajemen usaha.

c. Sumberdaya manusia. Sumberdaya manusia menjadi faktor pendukung pelaksanaan program. Dukungan pemateri bimbingan manajemen usaha yang kompeten di bidangnya menjadi faktor pendukung keberhasilan pelaksanaan program. 
d. Sumberdaya finansial (Anggaran). Sumberdaya finansial (anggaran) menjadi faktor penghambat pelaksanaan program. Anggaran program sangat terbatas dimana walaupun dalam Renstra Dinas Pemberdayaan Perempuan dan Perlindungan Anak Kota Samarinda masuk sebagai indikator kinerja pelayanan DP3A Kota Samarinda Tahun 2016-2021, namun program Desa PRIMA tidak masuk dalam program kerja prioritas yang mendapatkan anggaran dikarenakan defisit keuangan Pemkot Samarinda.

\section{REKOMENDASI}

1. Dari hasil wawancara, terdapat keluhan mengenai materi pelatihan yang dirasa rumit/tidak sesuai dengan kebutuhan sebagian peserta bimbingan manajemen usaha Desa PRIMA di Kelurahan Lok Bahu. Maka dari itu Kepala Dinas Pemberdayaan Perempuan dan Perlindungan Anak Kota Samarinda sebaiknya perlu melakukan pemetaan kebutuhan materi pelatihan sehingga pelatihan yang dilakukan tepat tujuan dan dapat diaplikasikan dalam pengembangan usaha perempuan di Kelurahan Lok Bahu Kota Samarinda.

2. Kurangnya motivasi perempuan untuk menekuni usahanya sehingga maju, tidak sekedar menjadi pekerjaan sambilan dan dapat meningkatkan kesejahteraan keluarga menjadi salah satu hambatan pelaksanaan program Desa PRIMA yang dihimpun pada saat melakukan wawancara, maka dari itu perlu dilakukan upaya peningkatan motivasi para pengusaha perempuan mengenai pentingnya berdaya secara ekonomi untuk menopang ekonomi keluarga (achievement motivation training). Diantaranya dengan cara memberikan seminar/pelatihan kewirausahaan yang menampilkan para perempuan wirausaha sukses sehingga hal ini akan menggugah semangat dan kemauan untuk maju tanpa melupakan kodratnya. Selain itu dapat juga dengan membangun jejaring antar sesama perempuan pelaku usaha dan pengusaha lokal sebagai pembelajaran usaha (learning by doing).

3. Program Desa PRIMA Kelurahan Lok Bahu sempat vakum kegiatannya dikarenakan keterbatasan anggaran maka dari itu diperlukan komitmen dari Kepala Dinas Pemberdayaan Perempuan dan Perlindungan Anak Kota Samarinda untuk terus konsisten mengawal program desa PRIMA sebagai salah satu program prioritas pemberdayaan ekonomi perempuan yang perlu mendapatkan anggaran sehingga tujuan program tercapai.

4. Program pemberdayaan perempuan banyak jenisnya dari berbagai instansi pemerintah maka dari itu perlu adanya pengembangan model sinergitas antar instansi/kementerian terkait pemberdayaan ekonomi perempuan dengan fokus pada satu desa/kelurahan dan masing masing instansi berkontribusi sesuai porsinya dan tidak tumpang tindih sehingga tujuan membangun desa yang mandiri tercapai (konsep whole of government).

\section{DAFTAR PUSTAKA}

Budiani, Ni Wayan. (2007). Efektivitas Program Penanggulangan Pengangguran Karang Taruna "Eka Taruna Bhakti" Desa Sumerta Kelod Kecamatan Denpasar Timur Kota Denpasar. Jurnal Ekonomi dan Sosial INPUT, Vol. 2(1): 49-57.

DP3A Kota Samarinda. (2016). Renstra DP3A Kota Samarinda Tahun 2016-2021. Samarinda.

Hadi, Sutrisno. (2009). Metodologi Penelitian. Yogyakarta: Andi Offset.

Kementerian Pemberdayaan Perempuan dan Perlindungan Anak RI. (2012). Kebijakan dan Strategi Peningkatan Produktifitas Ekonomi Perempuan (PPEP). Jakarta. 
Sardjo, Sulastri, Linda Darmajanti dan Koeshariyaningsih C. Boediono. (2016). Implementasi Model Evaluasi Formatif Program Pembangunan Sosial (EFPPS) : Partisipasi Multipihak dalam Evaluasi Program. Jakarta: Yayasan Pustaka Obor Indonesia.

SK Kepala Badan Pemberdayaan Masyarakat dan Perempuan No. 400/641/SKPP.3.1/VIII/2015 tanggal 13 Agustus 2015 tentang Penunjukan Desa PRIMA (Perempuan Indonesia Maju Mandiri) Tingkat Kota Samarinda Kelurahan Lok Bahu Kecamatan Sungai Kunjang. 